УДК 541.183:544.353.21

\author{
А. А. Эннан ${ }^{1}$, Р. Е. Хома ${ }^{1,2}$, Р. М. Длубовский ${ }^{1}$, Н. Н. Абрамова ${ }^{1}$, \\ Т. В. Михайлова ${ }^{1,3}$ \\ ${ }^{1}$ Физико-химический институт защиты окружающей среды и человека МОН и НАН \\ Украины, ул. Преображенская 3, Одесса, 65082, Украина; e-mail: eskvar@ukr.net \\ ${ }^{2}$ Одесский национальный университет имени И.И. Мечникова, \\ ул. Дворянская, 2, Одесса, 65082, Украина; email: rek@onu.edu.ua \\ ${ }^{3}$ Физико-химический институт им. А.В. Богатского НАН Украины, \\ Люстдорфская дорога, 86, Одесса, 65080, Украина

\section{ВОЛОКНИСТЫЙ ХЕМОСОРБЕНТ-АМФОЛИТ НА ОСНОВЕ КОМПЛЕКСНЫХ СОЕДИНЕНИЙ ХЛОРИДА НИКЕЛЯ (II)} \\ С ЭТИЛЕНДИАМИНОМ
}

\begin{abstract}
В статических условиях исследована сорбция паров воды комплексными соединениями хлорида никеля (II) с этилендиамином, нанесенным на волокнистый носитель при различном соотношении металл: лиганд. В статических и динамических условиях исследована хемосорбция оксида серы (IV) и аммиака полученными хемосорбентами. Установлено, что процесс хемосорбции $\mathrm{SO}_{2}$ может происходить только при наличии «свободной» воды, образующейся после завершения формирования монослоя. Показано, что полученный волокнистый хемосорбент осуществляет комбинированную очистку воздуха от оксида серы (IV) и аммиака и может быть использован для снаряжения средств индивидуальной защиты органов дыхания - облегченных газопылезащитных респираторов.
\end{abstract}

Ключевые слова: изотерма, хемосорбция, комплексообразование, этилендиамин, хлорид никеля, оксид серы (IV), аммиак.

В качестве средств индивидуальной защиты органов дыхания (СИЗОД) на предприятиях ряда отраслей промышленности (химической, металлургической, коксохимической) используются облегченные газопылезащитные респираторы на основе волокнистых хемосорбентов (XC) [1-3]. Для защиты от газообразных токсичных соединений различной химической природы используются специальные их марки (каждая для своей группы газов) [4], что создает определенные неудобства для ряда категорий работающих, которые по роду деятельности в течение смены выполняют работы в различных цехах.

Существуют также облегченные респираторы, которые в зависимости от природы токсичных газо (паро) подобных веществ состоят из нескольких слоев волокнистых XC, например ионообменных хемосорбционных материалов: анионита для поглощения кислых газов и катионита для поглощения основных газов [5]. Такие респираторы также имеют свои определенные недостатки, обусловленные многослойным составом противогазовых элементов, что усложняет конструкцию и повышает сопротивление воздушному потоку.

Сотрудниками Физико-химического института защиты окружающей среды и человека МОН и НАН Украины (г. Одесса) разработаны импортозамещающие однослойные импрегнированные волокнистые хемосорбенты-амфолиты (ИВХС-А), которые в зависимости от обстоятельств (условий эксплуатации) поглощают как кислые, так и основные газы [6-17]. Такие материалы получены путем пропитки нейтральных волокнистых носителей водными растворами со- 
лей многоосновных органических и минеральных кислот (лимонная, яблочная, оксиэтилендифосфоновая, этилендиаминтетрауксусная, ортофосфорная и др.) с азотсодержащими органическими основаниями (Am) [9, 10, 12-17]. Получены также ИВХС-А на основе комплексных соединений $3 \mathrm{~d}-$ металлов $\left(\mathrm{Ni}^{2+}, \mathrm{Cu}^{2+}\right)$ с аммиаком, моноэтаноламином (МЕА), гексаметилентетрамином (НМТА) и полиэтиленполиамином (РЕРА) [6-8, 11, 17].

В настоящей работе исследована принципиальная возможность использования еще одного представителя этого класса соединений - комплекса хлорида никеля (II) с этилендиамином (EDA) в качестве реагента для создания ИВХС-А (ИВХС$\mathrm{Ni}-\mathrm{EDA})$, предназначенного для поглощения кислых и основных газов в составе СИЗОД.

В случае комплексных соединений $\mathrm{Ni}(\mathrm{II})$ с амбидентантным MЕА лиганд координируется с $\mathrm{Ni}^{2+}$ через атомы кислорода и азота, образуя $\mathrm{Ni}-\mathrm{O}$ и $\mathrm{Ni} \neg \mathrm{N}$ связи $[18$, 19]. При этом в комплексах при соотношении Ni:MEA $<3,0$ во внутреннюю координационную сферу могут входить молекулы воды. Структурным производным MEA является EDA, который координируется с $\mathrm{Ni}^{2+}$ через атомы азота аминогруп; при соотношении Ni:EDA $<3,0$ внутреннюю координационную сферу дополняют ацидо-лиганды (например, $\mathrm{Cl}^{-}$) [20]. Указанные отличия при образовании комплексных соединений обуславливают определенный интерес к изучению влияния замены MEA на структурно подобный EDA в комплексных соединениях c $\mathrm{NiCl}_{2}$ на гидратационные и хемосорбционные (по отношению к $\mathrm{SO}_{2}$ и $\mathrm{NH}_{3}$ ) свойства полученных на их основе образцов ИВХС-А.

Целью настоящей работы было исследование хемосорбции оксида серы (IV) и аммиака ИВХC-Ni-EDA, полученного путем импрегнирования волокнистого материала (BM) водными растворами комплексных соединений хлорида никеля (II) с EDA при различном мольном соотношением Ni: N.

\section{МАТЕРИАЛЫ И МЕТОДЫ ИССЛЕДОВАНИЯ}

Для исследований в качестве носителя использовали нетканое иглопробивное полотно для фильтрации на основе лавсанового волокна (арт. 13 В230 (550) Н6,

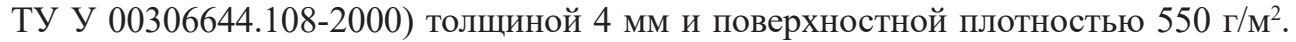
Для приготовления пропиточных растворов с заданным соотношением $\mathrm{Ni}: \mathrm{N}$ в 80 мл воды растворяли 15,0 г $\mathrm{NiCl}_{2} \cdot 6 \mathrm{H}_{2} \mathrm{O}$, затем при перемешивании добавляли необходимое количество EDA и доводили водой до 100 мл. Полученными растворами пропитывали ВМ из расчета 4,3 мл раствора на 1,0 г носителя до полного впитывания. Образцы высушивали на воздухе при температуре 20-25 $\mathrm{C}$.

Характеристики полученных образцов ИВХС приведены в табл. 1.

Исследования сорбционных характеристик ИВХС проводили в статических и динамических условиях сухими и увлажненными образцами.

В статических условиях сорбцию паров воды и оксида серы (IV) изучали в термостатированной при 298土0,2 К вакуумной установке с кварцевыми пружинными весами Мак-Бена-Бакра [23]. Вакуумирование осуществляли до постоянной массы с помощью форвакуумного насоса. Остаточное давление $(0,013$ Па) контролировали ионизационно-термопарным вакуумметром ВИТ-2М. Давление газа-сорбата регистрировали с помощью U-образного манометра по показаниям катетометра 
Таблица 1

Состав и устойчивость комплексов и характеристики ИВХC-Ni-EDA на их основе

Table 1

Composition and stability of the complexes and characteristics of IFCS - Ni - EDA

\begin{tabular}{|c|c|c|c|c|c|}
\hline $\begin{array}{l}\text { № } \\
\text { П/II }\end{array}$ & $\begin{array}{c}\text { Стехиометрическое } \\
\text { соотношение } \\
\mathrm{Ni}: \mathbf{N}(\mathbf{k}) \\
\end{array}$ & $\begin{array}{c}\text { Состав } \\
\text { комплекса } \\
{[20,21]} \\
\end{array}$ & $\underset{[22]}{\operatorname{lgK}}$ & $\begin{array}{c}\text { Содержание } \\
\text { NiCl }_{2}, \\
\text { мг/г носителя } \\
\end{array}$ & $\begin{array}{c}\text { Содержание EDA, } \\
\text { мг/г носителя }\end{array}$ \\
\hline 1 & $1,0: 0,5(0,5)$ & & & 351,7 & 40,8 \\
\hline 2 & 1,$0 ; 1,0(1)$ & & & 351,7 & 81,6 \\
\hline 3 & 1,$0 ; 2,0(2)$ & {$\left[\mathrm{Ni}(\mathrm{EDA}) \mathrm{Cl}_{2}\right]$} & 4,80 & 351,7 & 163,1 \\
\hline 4 & 1,$0 ; 3,0(3)$ & & & 351,7 & 244,7 \\
\hline 5 & 1,$0 ; 4,0(4)$ & {$\left[\mathrm{Ni}(\mathrm{EDA})_{2} \mathrm{Cl}_{2}\right]$} & 11,12 & 351,7 & 326,2 \\
\hline 6 & 1,$0 ; 5,0(5)$ & & & 351,7 & 407,8 \\
\hline 7 & 1,$0 ; 6,0(6)$ & {$\left[\mathrm{Ni}(\mathrm{EDA})_{3}\right] \mathrm{Cl}_{2}$} & 15,87 & 351,7 & 489,3 \\
\hline
\end{tabular}

КМ-6. Ошибка измерений не превышала \pm 2 \%. Кондиционирование образцов увлажнение до соответствующего условиям эксперимента влагосодержания - производили непосредственно в вакуумной установке до достижения состояния сорбционного равновесия при заданном значении относительного давления паров воды $P / P_{S}$. В динамических условиях исследования проводили с помощью специальной газодинамической установки, описанной в [24]. Концентрацию $\mathrm{SO}_{2}$ в газовоздушной смеси (ГВС) определяли с помощью электрохимического газоанализатора марки 667ЭХ10. Концентрацию $\mathrm{NH}_{3}$ в ГВС определяли ацидиметрически [25].

\section{РЕЗУЛЬТАТЫ ЭКСПЕРИМЕНТА И ИХ ОБСУЖДЕНИЕ}

Как известно $[24,26]$, при поглощении кислых газов различными хемосорбентами на основе Am, вода является не только реакционной средой, в которой осуществляются массообменные и хемосорбционные процессы, но и непременным участником последних. В этой связи вначале была исследована гидратация образцов ИВХC-Ni-EDA, полученных путем импрегнирования ВН водными растворами комплексных соединений $\mathrm{Ni}(\mathrm{II})$ с EDA. На рис. 1 представлены изотермы сорбции паров воды $a=f(P / P)$ образцами ИВXC-Ni-EDA при различном стехиометрическом соотношением $\mathrm{Ni}: \mathrm{N}$ в интервале $P / P_{S}=0 \div 0,95$.

Как видно из рис. 1 , увеличение количества лиганда в комплексах $\mathrm{NiCl}_{2}$ c EDA приводит к понижению гидрофильности полученных образцов ИВХС, в отличие от комплексов $\mathrm{NiCl}_{2}$ с $\mathrm{MEA}$ [27] и $\left[\mathrm{Cu}\left(\mathrm{NH}_{2}\left(\mathrm{CH}_{2} \mathrm{CH}_{2} \mathrm{NH}\right)_{n}-\mathrm{H}\right)_{\mathrm{k} /(\mathrm{n}+1)}\left(\mathrm{H}_{2} \mathrm{O}\right)_{\mathrm{m}}\right] \mathrm{SO}_{4}[28]$.

Приведенные изотермы имеют выпуклую относительно оси $P / P$ форму и относятся к III типу по классификации С. Брунауэра, Л. Деминга, У. Деминга, Э. Теллера [29]. Этот тип изотерм характерен для адсорбции газов и паров непористыми твердыми телами, при этом слабое взаимодействие адсорбент-адсорбат обуславливает небольшую величину адсорбции при низких значениях относительного давлений паров воды. 


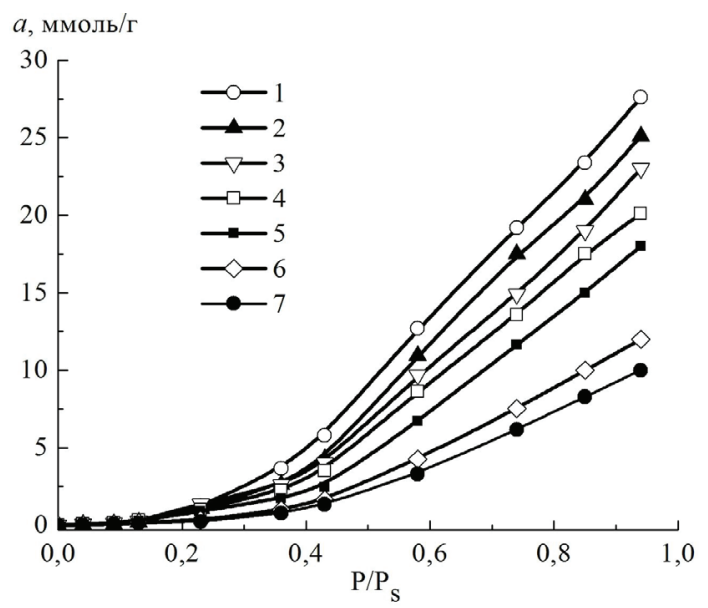

Рис. 1. Изотермы сорбции паров воды образцами ИВХC-Ni-EDA.

Fig. 1. Water vapor sorption isotherms by samples IFCS-Ni-EDA. k: $0,5-1 ; 1-2 ; 2-3 ; 3-4 ; 4-5 ; 5-6 ; 6-7$.

В статических условиях сухие образцы хемосорбентов $\mathrm{SO}_{2}$ практически не поглощают. Значительное увеличение количества сорбированного $\mathrm{SO}_{2}$ наблюдается после достижения значений $P / P_{S}>0,5$, когда образуются менее прочно связанные поверхностные гидратные слои, и появляется так называемая «свободная» вода, участвующая в процессе хемосорбции $\mathrm{SO}_{2}[24,26-28,30]$.

На рис. 2 приведены изотермы сорбции $\mathrm{SO}_{2}$ образцами ИВХC- Ni-EDA с различным соотношением $\mathrm{Ni}: \mathrm{N}$, увлажненными при $P / P_{S}=0,75$.

Форма изотерм с резким подъемом на начальном участке свидетельствует о хемосорбционном механизме связывания, когда основное количество сорбата поглощается уже при небольшом давлении $\mathrm{SO}_{2}$.

О количестве хемосорбированного образцами ИВXC-Ni-EDA оксида серы (VI) судили по приросту массы образцов после последующего вакуумирования, проводимого целью удаления физически сорбированных паров воды и $\mathrm{SO}_{2}$. Результаты приведены в табл. 2.

С увеличением содержания EDA в образцах ИВXC-Ni-EDA (при одном и том же содержании $\mathrm{Ni}^{2+}$ в них) растет величина хемосорбции (статической поглотительной емкости) по $\mathrm{SO}_{2}$ вплоть до значения $k=3,0$ (табл. 2; рис. 3, кривая 1). Дальнейшее увеличение $\mathrm{k}$ вплоть до 5,0 не приводит к существенным изменениям величины $\alpha\left(\mathrm{SO}_{2} \cdot \mathrm{H}_{2} \mathrm{O}\right)$; повышение $k$ от 5,0 до 6,0 сопровождается уменьшением величины $\alpha\left(\mathrm{SO}_{2} \cdot \mathrm{H}_{2} \mathrm{O}\right)$ в 1,3 раза. Очевидно, описанные эффекты обусловлены различием в строении комплексных соединений $\mathrm{NiCl}_{2}$ с $\mathrm{EDA}$ при разном стехиометрическом соотношении $\mathrm{Ni}: \mathrm{N}$. Изменение значений стехиометрического соотношения $\mathrm{Ni}(\mathrm{Cu}): \mathrm{N}(k)$ и а $\left(\mathrm{SO}_{2} \cdot \mathrm{H}_{2} \mathrm{O}\right)$ происходит симбатно в образцах ИВХC-Ni-MEA $(0,5 \leq k \leq 4,0)[27]$ и ИВХС-Сu-PЕРА $(1,0 \leq k \leq 6,0)[28]$ (рис. 3$)$. 


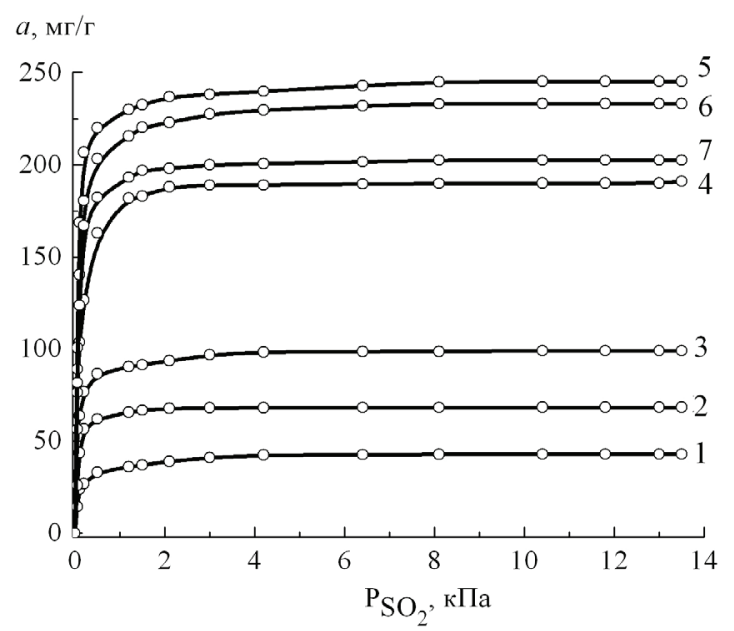

Рис. 2. Изотермы сорбции $\mathrm{SO}_{2}$ образцами ИВXC-Ni-EDA при $P / P_{s}=0,75$.

Fig. 2. $\mathrm{SO}_{2}$ sorption isotherms by samples IFCS-Ni-EDA at $P / P=0,75$. $\mathrm{k}: 0,5-1 ; 1-2 ; 2-3 ; 3-4 ; 4-5 ; 5-6 ; 6-7$.

\section{Результаты исследования хемосорбции оксида серы (IV)}

Таблица 2

ИВХC- Ni-EDA в статических условиях

Table 2

Sulfur dioxide chemisorption's investigations results by IFCS -Ni-EDA under static conditions

\begin{tabular}{|c|c|c|c|c|c|}
\hline $\begin{array}{l}\text { № } \\
\text { II/II }\end{array}$ & $\begin{array}{c}\text { Стехиометрическое } \\
\text { соотношение } \\
\mathbf{N i}: \mathbf{N}(k) \\
\end{array}$ & $\begin{array}{c}\text { Содержание } \\
\text { EDA в ИВХC, } \\
\text { мг/г }\end{array}$ & $\underset{\mathbf{M} \Gamma / \mathbf{\Gamma}}{\alpha\left(\mathbf{S O}_{2} \cdot \mathbf{H}_{2} \mathbf{O}\right) *}$ & $\underset{\mathbf{M \Gamma} / \mathbf{\Gamma}}{\alpha_{\mathrm{T} .}\left(\mathbf{S O}_{2} \cdot \mathbf{H}_{2} \mathbf{O}\right) * *}$ & $\begin{array}{c}\eta * * *, \\
\%\end{array}$ \\
\hline 1 & $1,0: 0,5(0,5)$ & 28,4 & 49,0 & 60,5 & 81,01 \\
\hline 2 & 1,$0 ; 1,0(1)$ & 48,4 & 67,7 & 103,0 & 65,74 \\
\hline 3 & 1,$0 ; 2,0(2)$ & 96,8 & 128,1 & 206,1 & 62,17 \\
\hline 4 & 1,$0 ; 3,0(3)$ & 132,4 & 246,5 & 281,9 & 87,45 \\
\hline 5 & 1,$0 ; 4,0(4)$ & 162,7 & 255,3 & 346,4 & 73,70 \\
\hline 6 & 1,$0 ; 5,0(5)$ & 187,8 & 255,8 & 399,9 & 63,97 \\
\hline 7 & 1,$0 ; 6,0(6)$ & 209,3 & 193,3 & 445,7 & 43,37 \\
\hline
\end{tabular}

$* \alpha\left(\mathrm{SO}_{2} \cdot \mathrm{H}_{2} \mathrm{O}\right)$ - величина хемосорбции $\mathrm{SO}_{2} \cdot \mathrm{H}_{2} \mathrm{O}\left(P / P_{s}=0,75 ; \mathrm{p}_{\mathrm{O}}=13,3\right.$ кПа $)$

** $\alpha\left(\mathrm{SO}_{2} \cdot \mathrm{H}_{2} \mathrm{O}\right) * *$ - теоретическое значение с учетом реакций $(6)^{2}$ и (7)

*** $\mathrm{h}$ - степень «срабатывания» $\mathrm{EDA}$

$* \alpha\left(\mathrm{SO}_{2} \cdot \mathrm{H}_{2} \mathrm{O}\right)-\mathrm{SO}_{2} \cdot \mathrm{H}_{2} \mathrm{O}$ chemisorption rate $\left(P / P=0,75 ; \mathrm{p}_{\mathrm{SO}}=13,3 \mathrm{kPa}\right)$

$* * \alpha_{\mathrm{T}}\left(\mathrm{SO}_{2} \cdot \mathrm{H}_{2} \mathrm{O}\right) * *-$ theoretical value taking into account reactions (6) and (7)

$* * * \mathrm{~h}-\mathrm{EDA}$ «triggering» degree 


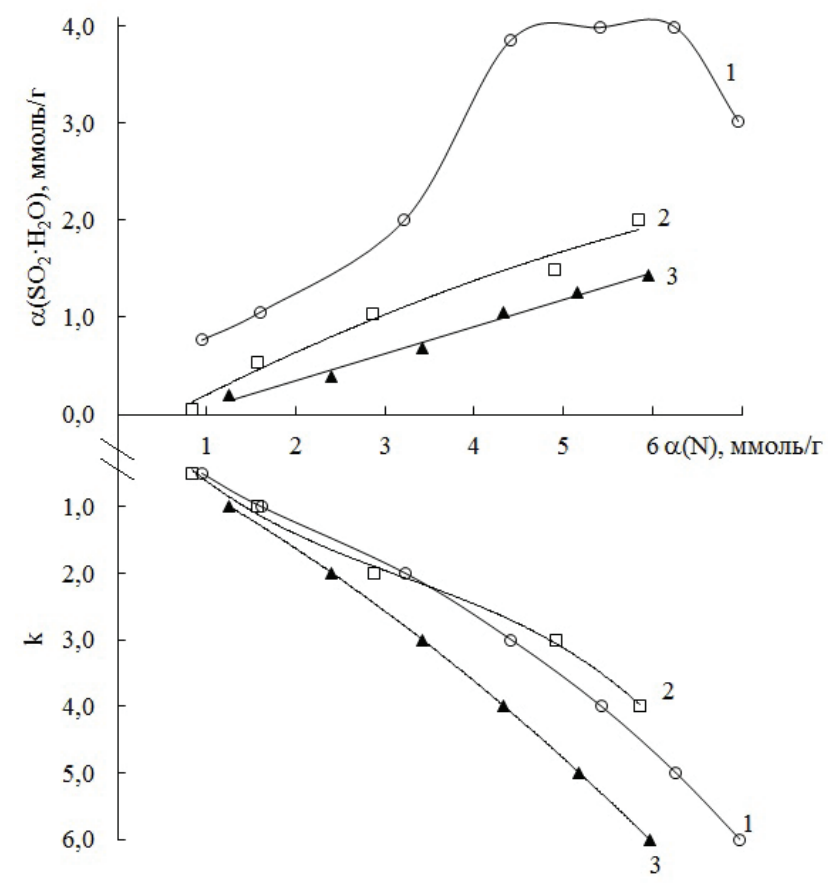

Рис. 3. Зависимость статической поглотительной емкости по $\mathrm{SO}_{2}\left(\alpha\left(\mathrm{SO}_{2} \cdot \mathrm{H}_{2} \mathrm{O}\right)\right.$, ммоль/г) и стехиометрического соотношения (k) образцов ИВХC-Ni-EDA (1), ИВХC-Ni-MEA (2) [27] и ИВХС-Cu-PEPA (3) [28] от содержания азота $((\alpha(\mathrm{N})$, ммоль/г).

Fig. 3. The dependence of the static absorption capacity on $\mathrm{SO}_{2}\left(\alpha\left(\mathrm{SO}_{2} \cdot \mathrm{H}_{2} \mathrm{O}\right), \mathrm{mmol} / \mathrm{g}\right)$ and the stoichiometric ratio $(k)$ of the samples IFCS - Ni - EDA (1), IFCS $-\mathrm{Ni}^{2}-\mathrm{MEA}(2)$ samples [27] and IFCS-Cu-PEPA (3) [28] on the nitrogen content $((\alpha(\mathrm{N}), \mathrm{mmol} / \mathrm{g})$.

В процессе взаимодействия ИВХC-Ni-EDA с оксидом серы (IV), очевидно, происходит разрушение донорно-акцепторной связи в нейтральных (реакции 1 и 2) комплексах и катионном (реакция 4) между ионами никеля (II) и внутрисферными $\mathrm{EDA}$ и $\mathrm{Cl}^{-}$с последующим образованием аммониевых сульфита, гидросульфита и пиросульфита (подобно [27]):

$$
\begin{gathered}
{\left[\mathrm{Ni}(\mathrm{EDA}) \mathrm{Cl}_{2}\right]+6 \mathrm{H}_{2} \mathrm{O} \stackrel{\mathrm{H}_{2} \mathrm{O}}{\rightarrow}\left[\mathrm{Ni}\left(\mathrm{H}_{2} \mathrm{O}\right)_{6}\right]^{2+}+\mathrm{EDA}+2 \mathrm{Cl},} \\
{\left[\mathrm{Ni}(\mathrm{EDA})_{2} \mathrm{Cl}_{2}\right]+6 \mathrm{H}_{2} \mathrm{O} \stackrel{\mathrm{H}_{2} \mathrm{O}}{\rightarrow}\left[\mathrm{Ni}\left(\mathrm{H}_{2} \mathrm{O}\right)_{6}\right]^{2+}+2 \mathrm{EDA}+2 \mathrm{Cl},} \\
{\left[\mathrm{Ni}(\mathrm{EDA})_{3}\right] \mathrm{Cl}_{2} \stackrel{\mathrm{H}_{2} \mathrm{O}}{\rightarrow}\left[\mathrm{Ni}(\mathrm{EDA})_{3}\right]^{2+}+2 \mathrm{Cl},} \\
{\left[\mathrm{Ni}(\mathrm{EDA})_{3}\right]^{2+}+6 \mathrm{H}_{2} \mathrm{O} \stackrel{\mathrm{H}_{2} \mathrm{O}}{\leftarrow}\left[\mathrm{Ni}_{2}\left(\mathrm{H}_{2} \mathrm{O}\right)_{6}\right]^{2+}+3 \mathrm{EDA},} \\
\mathrm{SO}_{2} \cdot \mathrm{H}_{2} \mathrm{O}+\mathrm{NH}_{2} \mathrm{CH}_{2} \mathrm{CH}_{2} \mathrm{NH}_{2} \rightarrow\left[\mathrm{NH}_{3} \mathrm{CH}_{2} \mathrm{CH}_{2} \mathrm{NH}_{3}\right]\left(\mathrm{SO}_{3}\right),
\end{gathered}
$$




$$
\begin{gathered}
\mathrm{SO}_{2} \cdot \mathrm{H}_{2} \mathrm{O}+\left[\mathrm{NH}_{3} \mathrm{CH}_{2} \mathrm{CH}_{2} \mathrm{NH}_{3}\right]\left(\mathrm{SO}_{3}\right) \rightarrow\left[\mathrm{NH}_{3} \mathrm{CH}_{2} \mathrm{CH}_{2} \mathrm{NH}_{3}\right]\left(\mathrm{HSO}_{3}\right)_{2}, \\
2\left[\mathrm{NH}_{3} \mathrm{CH}_{2} \mathrm{CH}_{2} \mathrm{NH}_{3}\right]\left(\mathrm{HSO}_{3}\right)_{2} \underset{\leftarrow}{\rightleftarrows}\left[\mathrm{NH}_{3} \mathrm{CH}_{2} \mathrm{CH}_{2} \mathrm{NH}_{3}\right] \mathrm{S}_{2} \mathrm{O}_{5}+\mathrm{H}_{2} \mathrm{O}
\end{gathered}
$$

Степень «срабатывания» $\mathrm{EDA}$ по $\mathrm{SO}_{2}$ с учетом образования гидросульфитов или пиросульфитов ( $\mathrm{S}: \mathrm{N}=1: 1)$ в статических условиях достигает $>85 \%$ (табл. 2). Известно $[27,28]$, что для образцов ИВХC-Ni-MEA и ИВХC-Cu-PEPA степень «срабатывания» MEA и РЕРА по оксиду серы (IV) с учетом образования только сульфитов ( $\mathrm{S}: \mathrm{N}=1: 2)$ составляет $<73 \%$ и $<55 \%$, соответственно.

С учетом литературных данных $[27,28]$ по способности хемосорбировать $\mathrm{SO}_{2}$ в статических условиях ИВХС-А можно расположить в следующий ряд:

$$
\text { ИВХС-Ni-EDA }>\text { ИВХС-Ni-MEA }>\text { ИВХС-Cu-PEРA. }
$$

Исследования хемосорбции $\mathrm{SO}_{2}$ и $\mathrm{NH}_{3}$ в динамическом режиме проводили в условиях, приближенных к реальной эксплуатации СИЗОД: концентрация $\mathrm{SO}_{2}$ в ГВС - $150 \mathrm{мг} / \mathrm{M}^{3}$ (15 ПДК), концентрация $\mathrm{NH}_{3}-160 \mathrm{m \Gamma} / \mathrm{M}^{3}$ (8 ПДК), относительная влажность ГВС $\varphi=90 \%$ (линейная скорость потока ГВС $-2,0$ cм $/ \mathrm{c}$, объемная $0,001 \mathrm{~m}^{3} / \mathrm{мин)}$. О защитной эффективности ИВХС судили по времени их защитного действия $\left(t_{\text {з.d., }}\right.$ мин) и динамической активности (ДА). Время защитного действия и ДА фиксировали в момент, когда концентрация $\mathrm{SO}_{2}\left(\mathrm{NH}_{3}\right)$ за слоем исследуемого материала составляла 1-3 мг/м³. ДА (мг $\left.\mathrm{SO}_{2}\left(\mathrm{NH}_{3}\right) / \Gamma\right)$ определяли по формуле:

$$
\text { ДА }=\frac{C \cdot V \cdot \tau}{m},
$$

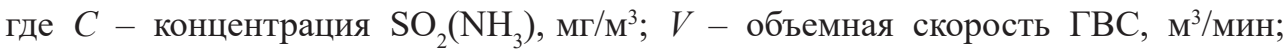
$m$ - масса исследуемого материала, г.

Результаты исследований сорбционных характеристик ИВХС-амфолита при поглощении оксида серы (IV) и аммиака в динамических условиях приведены в табл. 3.

Таблица 3

\begin{tabular}{|c|c|c|c|c|c|c|c|}
\hline \multirow{2}{*}{$\begin{array}{l}\text { № } \\
\text { п1/II }\end{array}$} & \multirow{2}{*}{$\begin{array}{c}\text { Стехиометрическое } \\
\text { соотношение } \\
\mathrm{Ni}: \mathbf{N}(k)\end{array}$} & \multicolumn{2}{|c|}{$\tau_{\text {з.д. }}$ мин } & \multicolumn{2}{|c|}{ ДА, мг/г } & \multicolumn{2}{|c|}{$\begin{array}{c}\text { Количество } \\
\text { поглощенного газа, мг }\end{array}$} \\
\hline & & $\mathrm{SO}_{2}$ & $\mathrm{NH}_{3}$ & $\mathrm{SO}_{2}$ & $\mathrm{NH}_{3}$ & $\mathrm{SO}_{2}$ & $\mathrm{NH}_{3}$ \\
\hline 1 & $1,0: 0,5(0,5)$ & 20 & 410 & 4,9 & 123,0 & 4,9 & 201 \\
\hline 2 & $1: 1(1)$ & 95 & 310 & 22,4 & 93,0 & 22,4 & 145 \\
\hline 3 & $1: 2(2)$ & 354 & 205 & 67,9 & 61,5 & 67,9 & 78,5 \\
\hline 4 & $1: 3(3)$ & 270 & 108 & 47,8 & 32,4 & 47,8 & 38,2 \\
\hline 5 & $1: 4(4)$ & 250 & 68 & 44,2 & 20,4 & 44,2 & 24,1 \\
\hline 6 & $1: 5(5)$ & 240 & 12 & 39,2 & 3,6 & 39,2 & 3,9 \\
\hline 7 & $1: 6(6)$ & 235 & 4 & 35,8 & 1,2 & 35,8 & 1,2 \\
\hline
\end{tabular}

Сорбционные характеристики ИВХC- Ni-EDA в динамических условиях

Table 3

Sorption's characteristics of IFCS -Ni-EDA under dinamic conditions 
Судя по приведенным в табл. 3 данным, полученный ИВХС может быть использован для поглощения кислых и основных газов при соотношении $\mathrm{Ni}: \mathrm{N}=$ $1: 1 \div 1: 3$. Время защитного действия существенно (в $1,5 \div 2,0$ раза) превышает аналогичные показатели существующих ИВХС-А на основе комплексных соединений сульфата меди (II) с аммиаком [11] и хлорида никеля (II) с MEA [6, 27] и HMTA [7].

Таким образом, волокнистый хемосорбент на основе комплексных соединений $\mathrm{NiCl}_{2}$ c EDA может найти применение для снаряжения СИЗОД - облегченных газопылезащитных респираторов.

\section{СПИСОК ЛИТЕРАТУРЫ}

1. Эннан А.А. Физико-химические основы улавливания, нейтрализации и утилизации сварочньх аэрозолей. Тр. 1-й Междунар. науч.-практ. конф. «Защита окружающей среды, здоровье, безопасность в свароч. производстве». - Одесса: Астропринт, 2002. - С. 10-37.

2. Эннан А.А., Байденко В.И. Сорбционно фильтрующие волокнистые иониты для индивидуальной противогазовой защиты (Обзор) // Экотехнологии и ресурсосбережение. - 2004. - № 5. - С. 43-54.

3. Эннан А.А., Байденко В.И., Захаренко Ю.С. Импрегнированные волокнистые хемосорбенты // Энерготехнологии и ресурсосбережение. - 2011. - № 1. - С. 50-56.

4. Басманов П.И., Каминский С.Л., Коробейникова А.В., Трубищына М.Е. Средства индивидуальной защиты органов дыхания. Справочное руководство. - СПб.: Искусство России, 2002. - 400 с.

5. Патент на корисну модель 57503 Україна, МПК А62В 7/00. Респіратор. / Еннан А.А.-А., Абрамова Н.М., Байденко В.І. - № u201012919; заявл. 01.11.2010; опубл. 25.02.2011, Бюл. № 4.

6. Патент України на корисну модель заявка UA 96010, МПК B01D 39/00 Склад для просочування фільтруючого матеріалу. Еннан А.А.-А., Длубовський Р.М., Хома Р.Є., Абрамова Н.М., Наумчак В.А. №u201409000; заявл. 11.08.2014; опубл. 12.01.2015, Бюл. № 1.

7. Патент України на корисну модель UA 107184, МПК B01D 39/00 Склад для просочування фільтруючого волокнистого матеріалу. Еннан А.А.-А., Хома Р.С., Абрамова Н.М., Длубовський Р.М., Гусельникова Н.О. № u201511537; заявл. 23.11.2015; опубл. 25.05.2016, Бюл. № 10 .

8. Патент України на корисну модель. UA 109661, МПК B01D 39/00 Нетканий сорбційно-фільтруючий волокнистий амфоліт з індикацією «спрацьовування» динамічної поглинальної ємкості. Еннан А.А.-А., Длубовський Р.М, Хома Р.С., Абрамова Н.Н., Селівестров О.А. № u201603009; заявл. 23.03.2016; опубл. 25.08.2016, Бюл. № 16.

9. Патент України на винахід UA 115534, МПК B01D 39/00 Просочуючий склад для одержання хемосорбенту-амфоліту. Еннан А.А.-А., Хома Р.С., Галак А.В., Захаренко Ю.С., Абрамова Н.М. № u201608804; заявл. 15.08.2016; опубл. 25.04.2017, Бюл. № 8 .

10. Патент України на винахід UA 116964, МПК D 06М 13/00 Просочуючий склад для одержання хемосорбенту-амфоліту / Еннан А.А., Хома Р.С., Длубовський Р.М., Абрамова Н.М. - № а201707157; Заявл. 07.07.2017; Опубл. 25.05.2018, Бюл. №10.

11. Патент України на корисну модель UA 124236, МПК В01J 20/00, В01J 20/32, B01D 39/00 Склад для просочування фільтруючого матеріалу. Еннан А.А., Хома Р.С., Длубовський Р.М., Абрамова Н.М. № u201711129. Заявл. 31.11.2017. Опубл. 26.03.2018, Бюл. № 6.

12. Патент України на корисну модель UA 124684, МПК B01D 39/00 Просочуючий склад для одержання хемосорбенту-амфоліту. Еннан А.А., Хома Р.С., Захаренко Ю.С., Абрамова Н.М. - № u201707156. Заявл. 07.07.2017. Опубл. 25.04.2018, Бюл. № 8.

13. Патент України на корисну модель UA 129785, МПК B01D 39/00 Склад для просочування фільтруючого матеріалу / Еннан А.А., Хома Р.С., Захаренко Ю.С., Абрамова Н.М., Грідяєв В.В. № u201805458; заявл. 16.05.2018; опубл. 12.11.2018, Бюл. № 21.

14. Патент України на корисну модель UA 133694, МПК B01D 39/00 Просочуючий склад для одержання хемосорбенту-амфоліту. Еннан А.А., Хома Р.Є., Длубовський Р.М., Абрамова Н.М. - № u201808221. Заявл. 25.07.2018. Опубл. 25.04.2019, Бюл. № 8. 
15. Патент України на корисну модель UA 135209 MПК B01D 39/00. Просочуючий склад для одержання хемосорбенту-амфоліту Еннан А.А., Хома Р.С., Длубовський Р.М., Абрамова Н.М., Грідяєв В.В. № u201812907; заявл. 26.12.2018; опубл. 25.06.2019, Бюл. № 12 .

16. Патент України на корисну модель UA 135921 МПК B01D 39/00. Просочуючий склад для одержання хемосорбенту-амфоліту Еннан А.А., Хома Р.С., Захаренко Ю.С., Абрамова Н.М. № u201901449; заявл.13.02.2019; опубл. 25.07.2019, Бюл. № 14.

17. Еннан А., Длубовський Р., Хома Р., Захаренко Ю., Абрамова Н., Грідяєв В. Імпрегновані волокнисті хемосорбенти-амфоліти з індикацією «спрацьовування» динамічної поглинальної ємності. // Збірник науков. праць XVI наук. конф. «Львівські хімічні читання». - Львів. 2-5 червня 2019. - С. 3124.

18. Masoud M.S., Abou El-Enein S.A., Abed I.M., Ali A.E. Synthesis and Characterization of Amino Alcohol Complexes // J. Coord. Chem. - 2002. - Vol. 55, N 2. - P. 153-178. http://dx.doi.org/10.1080/00958970211879

19. Yeşsilel O.Z., Şahin E. Vitamin B13 Complexes of Nickel(II) and Copper(II) with Ethanolamine: Syntheses, Crystal Structures, Spectroscopic and Thermal Studies // Z. Anorg. Allg. Chem. - 2007. - Vol. 633, N 7. P. 1087 -1093. https://doi.org/10.1002/zaac.200700049

20. De G., Biswas P.K., Chaudhuri N.R. Thermal Investigation of Nickel(II) Diamine Complexes in Solid State // Bull. Chem. Soc. Jpn. - 1983. - Vol. 56, N 10. - P. 3145-3151. https://doi.org/10.1246/bcsj.56.3145

21. Noorania N., Rahemib H., Tayyaric S.F. Conformational Stabilities, EPR, IR and VCD Studies of Tris(ethylenediamine)nickel(II) Chloride // J. Iran. Chem. Soc. - 2010. - Vol. 7, N 4. - P. 934-945. https://doi. org/10.1007/bf03246089

22. Астафьева Е., Золотарева А., Щеглова Н., Попова Т. Смешанолигандные комплексы меди (II) и никеля (II) с диаминами // Сб статей XIV Всеросс. конф. «Структура и динамика молекулярных систем». Яльчик, 2007. - № 1. - С. 364-367.

23. Кельиев Н.В. Основы адсорбционной техники. - М.: Химия, 1984. - 592 с.

24. Эннан А.А., Длубовский Р.М., Абрамова Н.Н., Хома Р.Е. Хемосорбция оксида серы (IV) волокнистыми материалами, импрегнированными полиэтиленполиамином. 2. Изучение влияния предадсорбции паров воды на хемосорбцию SO2 волокнистыми матеріалами. // Вестник ОНУ. Химия. - 2014. - Т. 19, № 3. C. 20-30. http://dx.doi.org/10.18524/2304-0947.2014.3(51).40356

25. ГОСТ 12.4.159-90. Средства индивидуальной защиты органов дыхания фильтрующие. Методы определения времени защитного действия фильтрующее-поглощающих коробок по газообразным вредным веществам.

26. Еннан А.А.-А., Хома Р.С. Імпрегновані волокнисті хемосорбенти кислих газів респіраторного призначення // Вісник ОНУ. Хімія. - 2017. - Т. 22, № 4. - С. 53-68. http://dx.doi.org/10.18524/23040947.2017.4(64).115924

27. Хома Р.Е., Эннан А.А., Длубовский Р.М., Абрамова Н.Н. Волокнистый хемосорбент оксида серы (IV) и аммиака на основе комплексных соединений хлорида никеля(II) с моноэтаноламином // Вісник ОНУ. Хімія. - 2016. - Т. 21, № 1. - С. 92-101. http://dx.doi.org/10.18524/2304-0947.2016.1(57).67515

28. Эннан А.А.-А., Хома Р.Е., Длубовский Р.М., Гридяев В.В., Михайлова Т.В. Волокнистый хемосорбент оксида серы (IV) на основе комплексных соединенй сульфата меди (II) с полиэтиленполиамином. // Вісник ОНУ. Хімія. - 2018. - Т. 23, № 2. - С. 95-105. http://dx.doi.org/10.18524/2304-0947.2018.2(66).132053

29. Киселев А.В. Экспериментальные методы в адсорбции и молекулярной хроматографии. - М.: Изд-во МГУ, 1973. - $447 \mathrm{c}$

30. Эннан А.А., Байденко В.И. К механизму сорбции тетрафторида кремния анионитами. Сообщ. 1. Роль воды // Вопросы химии и хим. технологии. - 2005. - № 6. - С. 64-68.

Стаття надійшла до редакції 02.07.2019 


\section{А. А.-А. Еннан ${ }^{1}$, Р. Є. Хома ${ }^{1,2}$, Р. М. Длубовський ${ }^{1}$ Н. М. Абрамова ${ }^{1}$,}

Т. В. Михайлова ${ }^{1,3}$

${ }^{1}$ Фізико-хімічний інститут захисту навколишнього середовища і людини МОН та

НАН України, вул. Преображенська 3, Одеса, 65082, Україна;

e-mail: eskvar@ukr.net

${ }^{2}$ Одеський національний університет імені I.I. Мечникова,

вул. Дворянська, 2, Одеса, Україна, 65082; email: rek@onu.edu.ua

${ }^{3}$ Фізико-хімічний інститут ім. О.В. Богатського НАН України,

Люстдорфська дорога, 86, Одеса, Одеська область, 65080, Україна

\section{ВОЛОКНИСТИЙ ХЕМОСОРБЕНТ-АМФОЛІТ НА ОСНОВІ КОМПЛЕКСНИХ СПОЛУК ХЛОРИДУ НІКЕЛЮ (II) 3 ЕТИЛЕНДІАМНОМ}

У роботі досліджена принципова можливість використання комплексу хлориду нікелю (II) $з$ етилендіаміном (EDA) як реагенту для створення імпрегнованих волокнистих хемосорбентів-амфолітів (IBXC-A), які в залежності від умов експлуатації здатні поглинати як кислі $\left(\mathrm{SO}_{2}\right)$, так і основні $\left(\mathrm{NH}_{3}\right)$ гази.

У статичних умовах досліджена сорбція пари води зразками IBXC-Ni-EDA, отриманих шляхом імпрегнування волокнистого матеріалу водними розчинами комплексних сполук хлориду нікелю (II) з EDA при різному стехіометричному співвідношенні $\mathrm{Ni}$ : $\mathrm{N}(1 / k)$. Встановлено, що збільшення кількості EDA у комплексі $3 \mathrm{NiCl}_{2}$ призводить до зниження гідрофільності отриманих зразків IBXC-А. Ізотерми адсорбції води мають опуклу щодо осі $P / P_{\text {s }}$ форму і відносяться до III типу за класифікацією С. Брунауера, Л. Лемінга, У. Деминга і Е. Теллєра. Даний тип ізотерм характерний для адсорбції газів і парів непористими твердими тілами, при цьому слабка взаємодія адсорбент-адсорбат обумовлює невелику величину адсорбції при низьких значеннях відносного тисків парів води.

У статичних і динамічних умовах досліджено поглинання оксиду сірки (IV) отриманими зразками IBXC-Ni-EDA. Показано, що процес поглинання $\mathrm{SO}_{2}$, що перебігає переважно за хемосорбційним механізмом, відбувається лише при наявності «вільної» води 3 утворенням на поверхні волокон носія діамонієвого гідросульфіту (піросульфіту). Встановлено, що значення величини статичної хемосорбції $\mathrm{SO}_{2} \cdot \mathrm{H}_{2} \mathrm{O}$ збільшуються 3 ростом вмісту EDA до значення $\mathrm{k}=3,0$ в зразках IBXC-Ni-EDA. 3 врахуванням літературних даних показано, що за властивістю хемосорбувати оксид сірки (IV) у статичних умовах IBXC-А можна розташувати в такий ряд:

$$
\text { IBXC-Ni-EDA }>\text { IBXC-Ni-MEA }>\text { IBXC-Cu-PEPA. }
$$

Показано, що отриманий IBXC-Ni-EDA може бути використаний для поглинання кислих і основних газів при співвідношенні $\mathrm{Ni}: \mathrm{N}=1: 1 \div 1: 3$. Час захисної дії IBXC$\mathrm{Ni}-\mathrm{EDA}$ істотно (в 1,5 $\div 2,0$ рази) перевищує аналогічні показники існуючих IBXC-A на основі комплексних сполук сульфату міді (II) 3 аміаком і хлориду нікелю (II) 3 моноетаноламіном і гексаметилентетраміном.

IBXC-Ni-EDA рекомендується застосовувати для спорядження засобів захисту органів дихання - полегшених газопилозахисних респіраторів.

Ключові слова: хемосорбція, комплексоутворення, етилендіамін, хлорид нікелю (II), оксид сірки (IV), аміак, ізотерма. 


\author{
A. A. Ennan ${ }^{1}$, R. E. Khoma ${ }^{1,2}$, R. M. Dlubovskiy ${ }^{1}$, N. N. Abramova ${ }^{1}$, \\ T. V. Mikhaylova ${ }^{1,3}$ \\ ${ }^{1}$ Physico-Chemical Institute of Environment and Human Protection, \\ Preobrazhenskaya str., 3, Odessa, 65082, Ukraine; eksvar@ukr.net \\ ${ }^{2}$ Odessa I.I. Mechnikov National University, Dvoryankaya str., 2 , \\ Odessa,65082,Ukraine; rek@onu.edu.ua \\ ${ }^{3}$ A.V. Bogatsky Physico-chemical Institute of National Academy of Science of Ukraine. \\ Lustdorfskaya doroga 86, Odessa, 65080, Ukraine.
}

\title{
FIBROUS CHEMISORBENT-AMFOLITE BASED ON THE COMPLEX COMPOUNDS OF NICKEL (II) CHLORIDE AND ETHYLENEDIAMINE
}

The principal possibility of using the nickel (II) chloride complex with ethylenediamine (EDA) as a reagent for the creation of impregnated fibrous chemisorbents-amfolite (IFCS-A), which depending on the operating conditions can absorb acidic $\left(\mathrm{SO}_{2}\right)$ and basic $\left(\mathrm{NH}_{3}\right)$ gases, has been investigated.

The sorption of water vapor by IFCS-Ni-EDA, obtained by impregnating a fibrous material with aqueous solutions of nickel (II) chloride complexes with EDA at different molar ratios $\mathrm{Ni}$ : $\mathrm{N}(1 / k)$ was determined under static conditions, the nature of the effect of the pre-absorbed water on this process was stated. It was found the increasing the amount of EDA in combination with $\mathrm{NiCl}_{2}$ to decrease in the hydrophilicity of the obtained IFCS-A samples. Water adsorption isotherms are convex with respect to the $P / P_{\mathrm{s}}$ axis and are of type III according to C. Brunauer, L. Deming, U. Deming, E. Teller classification. This type of isotherms is characteristic of the adsorption of gases and vapors by non-porous solids, and the weak adsorbentadsorbate interaction causes a small amount of adsorption at low values of the relative vapor pressures of water.capacity and the heat of sorption of water molecules in the first layer has been determined.

Under static and dynamic conditions the absorption of sulfur dioxide by the obtained IFCS$\mathrm{Ni}-\mathrm{EDA}$ samples was studied. It is shown the $\mathrm{SO}_{2}$ uptake process, going predominantly through the chemisorption mechanism, occurs only in the presence of «free» water formed with the formation of diamonium hydrosulfite (pyrosulfite) on the carrier fibers surface.

It has been established the values of the $\mathrm{SO}_{2} \cdot \mathrm{H}_{2} \mathrm{O}$ static chemisorption increase with increasing EDA content to $k$ value in IFCS-Ni-EDA samples. Taking into account the literature data it is shown that the property of sulfur dioxide chemisorbing under static conditions of IFCS-A can be placed in the order:

$$
\text { IFCS-Ni-EDA }>\text { IFCS-Ni-MEA }>\text { IFCS-Cu-PEPA. }
$$

It is shown that the obtained IFCS-Ni-EDA can be used for absorption of acidic and basic gases at $\mathrm{Ni}: \mathrm{N}=1: 1 \div 1: 3$. ratio. The protective action time of substantially IFCS-Ni-EDA $(1.5 \div 2.0$ times $)$ exceeds the analogous values of existing IFCS-A based on complex compounds of copper (II) sulfate with ammonia and nickel (II) chloride with monoethanolamine and hexamethylenetetramine.

IFCS-Ni-EDA is recommended for use in equipping of respiratory protection devices - lightweight gas-dust respirators.

Keywords: chemisorption, complexation, ethylenediamine, nickel(II) chloride, sulfur dioxide, ammonia, isotherm. 


\section{REFERENCES}

1. Ennan A.A. Fiziko-himicheskie osnovy ulavlivanija, nejtralizacii i utilizacii svarochnyh ajerozolej. Book of $1^{\text {st }}$ Internatonal Science-Practical Conference «Protection of Environment, Health, and Safety in Welding» (Odessa, 11-13 September 2002), Odessa, Astroprint, 2002, pp. 10-37. (in Russian)

2. Ennan A.A., Baidenko V.I. Sorbcionno fil trujushhie voloknistye ionity dlja individual'noj protivogazovoj zashhity (Obzor). Jenergotehnologii i resursosberezhenie, 2004, no 5, pp. 43-54. (in Russian)

3. Ennan A.A., Baidenko V.I., Zakharenko Yu.S. Impregnirovannye voloknistye hemosorbenty. Jenergotehnologii i resursosberezhenie, 2011, no 1, pp. 50-56. (in Russian)

4. Basmanov P.I., Kaminskij S.L., Korobejnikova A.V., Trubicyna M.E. Respiratory Protective Devices. Reference Guide. SPb, Iskusstvo Rossii, 2002, 400 p. (in Russian)

5. Ennan A.A.-A., Abramova N.M., Baidenko V.I. Respirator Patent UA, no 57503, publ. 25.02 .2011 (in Ukrainian)

6. Ennan A.A.-A., Dlubovskiy R.M., Khoma R.E., Abramova N.M., Naumchak V.A. Composition for the Filter Material Impregnation. Patent UA, no 96010, publ. 12.01.2015 (in Ukrainian)

7. Ennan A.A.-A., Khoma R.E., Abramova N.M., Dlubovskiy R.M., Gusel'nikova N.O. Composition for Impregnating Filter Materials. Patent UA, no 107184, publ. 23.11.2015 (in Ukrainian)

8. Ennan A.A.-A., Dlubovskiy R.M., Khoma R.E., Abramova N.M., Selivestrov O.A. Netkanij sorbcijnofil 'trujuchij voloknistij amfolit z indikacieju «sprac'ovuvannja» dinamichnö̈ poglinal'noï emkosti. Patent UA, no 109661, publ. 25.08.2016. (in Ukrainian)

9. Ennan A.A.-A., Khoma R.E., Galak A.V., Zakharenko Yu.S., Abramova N.M. Impregnated Composition for Obtaining Chemosorbent-Ampholyte. Patent UA, no 115534, publ. 25.04.2017 (in Ukrainian)

10. Ennan A.A.-A., Khoma R.E., Dlubovskiy R.M., Abramova N.M. Impregnated Composition for Obtaining Chemosorbent-Ampholyte. Patent UA, no 116964, publ. 25.05.2018 (in Ukrainian)

11. Ennan A.A.-A., Khoma R.E., Dlubovskiy R.M., Abramova N.M. Composition for Impregnating Filter Materials. Patent UA, no 124236, publ. 26.03.2018 (in Ukrainian)

12. Ennan A.A.-A., Khoma R.E., Zakharenko Ju.S., Abramova N.M. Impregnated Composition for Obtaining Chemosorbent-Ampholyte. Patent UA, no 124684, publ. 25.04.2018 (in Ukrainian)

13. Ennan A.A.-A., Khoma R.E., Zakharenko Ju.S., Abramova N.M., Gridjaev V.V. Composition for Impregnating Filter Materials. Patent UA, no 129785, publ. 12.11.2018 (in Ukrainian)

14. Ennan A.A.-A., Khoma R.E., Dlubovskiy R.M., Abramova N.M. Impregnated Composition for Obtaining Chemosorbent-Ampholyte. Patent UA, no 133694, publ. 25.04.2019 (in Ukrainian)

15. Ennan A.A.-A., Khoma R.E., Dlubovskiy R.M., Abramova N.M., Gridjaev V.V. Impregnated Composition for Obtaining Chemosorbent-Ampholyte. Patent UA, no 135309, publ. 25.06.2019 (in Ukrainian)

16. Ennan A.A.-A., Khoma R.E., Zakharenko Ju.S., Abramova N.M. Impregnated Composition for Obtaining Chemosorbent-Ampholyte. Patent UA, no 135921, publ. 13.02.2019 (in Ukrainian)

17. Ennan A., Dlubovskiy R., Khoma R.E., Zakharenko Ju., Abramova N., Gridjaev V. Impregnated Fibrous Chemisorbents-Amfolites with indication of dynamic sorptive capacity «wearing». Coll. sci. works of XVI sci. conf. «Lviv chemical reading - 2019». L’viv, pp. 3124. (in Ukrainian)

18. Masoud M.S., Abou El-Enein S.A., Abed I.M., Ali A.E. Synthesis and Characterization of Amino Alcohol Complexes. J. Coord. Chem., 2002, vol. 55, no 2, pp. 153-178. http://dx.doi.org/10.1080/00958970211879

19. Yeşsilel O.Z., Şahin E. Vitamin B13 Complexes of Nickel(II) and Copper(II) with Ethanolamine: Syntheses, Crystal Structures, Spectroscopic and Thermal Studies. Z. Anorg. Allg. Chem., 2007, vol. 633, no 7, pp. 1087 -1093. https://doi.org/10.1002/zaac.200700049

20. De G., Biswas P.K., Chaudhuri N.R. Thermal Investigation of Nickel(II) Diamine Complexes in Solid State. Bull. Chem. Soc. Jpn., 1983, vol. 56, no 10, pp. 3145-3151. https://doi.org/10.1246/bcsj.56.3145

21. Noorania N., Rahemib H., Tayyaric S.F. Conformational Stabilities, EPR, IR and VCD Studies of Tris(ethylenediamine)nickel(II) Chloride. J. Iran. Chem. Soc., 2010, vol. 7, no 4, pp. 934-945. https://doi. org/10.1007/bf03246089

22. Astaf'eva E., Zolotareva A., Shheglova N., Popova T. Smeshanoligandnye kompleksy medi (II) $i$ nikelja (II) $s$ diaminami. Sb statej XIV Vseross. konf. «Struktura i dinamika molekuljarnyh sistem». Jal’chik, 2007, no 1, pp. 364-367. (in Russian)

23. Keltsev N.V. Principles of adsorption technique. Moscow, Chemistry, 1984, 592 p. (in Russian)

24. Ennan A.A., Dlubovskiy R.M., Abramova N.N., Khoma R.E. Chemisorption of sulfur dioxide by polyethylene polyamine impregnated fibrous materials. 2. The study of water vapor influence on preadsorbtion $\mathrm{SO}_{2}$ chemisorption by fibrous materials. Vìsn. Odes. nac. unìv., Hìm., 2014, vol. 19, no 3, pp. 20-30. http://dx.doi. org/10.18524/2304-0947.2014.3(51).40356 (in Russian) 
25. GOST 12.4.159-90. Sredstva individual'noj zashhity organov dyhanija fil trujushie. Metody opredelenija vremeni zashhitnogo dejstvija fil 'trujushhe-pogloshhajushhih korobok po gazoobraznym vrednym veshhestvam. (in Russian)

26. Ennan A.A.-A., Khoma R.E. Impregnated Fibrous Acid Gases Chemosorbents for Respiratory Purpose. Visn. Odes. nac. univ, 2017, vol. 22, no 4, pp. 53-68. http://dx.doi.org/10.18524/2304-0947.2017.4(64).115924 (in Ukranian)

27. Khoma R.E., Ennan A.A., Dlubovskiy R.M., Abramova N.N. Fibrous Chemisorbents-Ampholyte Based on the Complex Compound of Nickel(II) Chloride and Monoethanolamine. Visn. Odes. nac. univ., 2016, vol. 21, no 1, pp. 92-101. http://dx.doi.org/10.18524/2304-0947.2016.1(57).67515 (in Russian)

28. Ennan A.A.-A., Khoma R.E., Dlubovskiy R.M., Abramova N.N., Gridjaev V.V., Mikhaylova T.V. Fibrous Chemisorbent of Sulfur Dioxide Based on the Complex Compounds of Cooper (II) Sulphate and Polyethylenepolyamine. Visn. Odes. nac. univ., 2018, vol. 23, no 2, pp. 95-105. https://doi.org/10.18524/23040947.2018.2(66).132053 (in Russian)

29. Kiselev A.V. Experimental Methods in Adsorption and Chromatography. Moscow, Izd. MGU, 1973, 447 p. (in Russian)

30. Ennan A.A., Baidenko V.I. Mechanism of silicon tetrafluoride sorption by anionites. I. Role of water. Issues of Chemistry and Chemical Technology, 2005, no 6, pp. 64-68. (in Russian). 